\title{
Aplikasi Mobile Wallet Menggunakan Teknik Personal Financial Management (PFM) Pendukung Kecerdasan Bisnis
}

\author{
Rahmad Syah, M. K. M Nasution'1, Erna Budhiarti Nababan², Syahril Efendi ${ }^{3}$ \\ Fakultas Ilmu Komputer dan Teknologi Informasi, Universitas Sumatera Utara. \\ Padang Bulan 20155 USU. Medan. \\ bayurahmadsyah45@gmail.com
}

\begin{abstract}
Abstrak- Teknologi memainkan peran penting sehingga sistem pendidikan terus bergerak secara dinamis dan inovatif. Dalam penelitian ini Fintech menggunakan manajemen keuangan pribadi (PFM) yang dapat memberikan analisis analisis keuangan pribadi, penilaian kesehatan keuangan pribadi, dan layanan rekomendasi produk keuangan yang terdiri dari produk investasi, asuransi dan alat untuk memantau dan mengontrol tingkat pengeluaran agar sesuai dengan perencanaan. menargetkan keuangan pelanggan, serta menyediakan layanan pembayaran online yang dapat membantu dalam proses transaksi pembayaran yang lebih mudah, fleksibel, dan cepat. Fintech disajikan dalam bentuk pembayaran seluler berbasis Android.
\end{abstract}

Kata Kunci: Star-Up, Aplikasi Mobile, Personal Financial Management

Abstract- Technology plays an important role so that the education system continues to move dynamically and innovatively. In this research, Fintech uses personal financial management (PFM) which can provide analysis of personal financial analysis, personal financial health assessment, and financial product recommendation services consisting of investment products, insurance and tools to monitor and control the level of expenditure to match planning. target customer finances, and provide online payment services that can help in the payment process that is easier, more flexible, and faster. Fintech is presented in the form of Android-based cellular payments.

Keywords: Star-Up, Mobile Applications, Personal Financial Management

\section{PENDAHULUAN}

Teknologi Keuangan (FinTech) muncul bersamaan dengan perubahan gaya hidup masyarakat yang saat ini didominasi oleh pengguna teknologi informasi yang bergerak cepat [1]. Definisi Fintech dalam peraturan Bank Indonesia Nomor 19/12/PBI/2017 adalah penggunaan teknologi sistem keuangan yang menghasilkan produk, layanan, teknologi dan / atau model bisnis baru dan dapat berdampak pada stabilitas moneter, stabilitas sistem keuangan, dan juga hasil dalam sistem pembayaran yang efisien, aman dan andal. Penyedia teknologi keuangan meliputi sistem pembayaran, dukungan pasar, manajemen investasi dan manajemen risiko, pinjaman, penyedia pembiayaan dan modal, dan layanan keuangan lainnya [2]. Karena perkembangan terbaru dalam teknologi IT, berbagai teknologi Fintech sedang dikembangkan. Terutama, karena kebutuhan akan layanan pembayaran seluler yang memungkinkan pembayaran mudah. Sebagai bagian dari solusi yang coba diakomodasi oleh industri fintech, layanan pembayaran seluler akan menjadi salah satu faktor yang berpengaruh, khususnya 
dalam fintech vertikal dan dalam lanskap kekayaan [3]. Ini didasarkan pada statistik yang menunjukkan bahwa pertumbuhan smartphone telah melebihi kepemilikan rekening bank. Sistem pendidikan di Indonesia telah mengalami transformasi digital. Teknologi memainkan peran penting sehingga sistem pendidikan terus bergerak secara dinamis dan inovatif [4]. Salah satunya adalah penggunaan Fintech berbasis mobile di universitas [5,6]. Dalam studi ini, Fintech menyediakan layanan pembayaran online yang dapat membantu siswa dalam proses transaksi pembayaran yang lebih mudah, fleksibel dan cepat $[7,8]$. Fintech menggunakan manajemen keuangan pribadi (PFM) yang dapat memberikan analisis keuangan pribadi, penilaian kesehatan keuangan pribadi, dan layanan rekomendasi produk keuangan yang terdiri dari produk investasi, asuransi, dan alat untuk memantau dan mengontrol tingkat pengeluaran agar sesuai dengan target perencanaan keuangan pelanggan $[9,10]$.

\section{METODOLOGI PENELITIAN}

Merchant: adalah tempat yang mengakomodasi detail transaksi pelanggan. Data mencakup elemen statis dan dinamis yang mengidentifikasi setiap transaksi $[11,12]$. Pelanggan menerima data transaksi dari Pedagang dan mencocokkan setiap informasi yang mereka miliki di mana format pembayaran standar telah disiapkan untuk dapat memproses pembayaran. Proses pembayaran melalui mitra tepercaya seperti bank atau operator telekomunikasi $[13,14]$. Ketika permintaan pembayaran siap untuk ditransfer, konsumen memeriksa dan mengidentifikasi dengan PIN yang dikirimkan oleh manajer akun. Manajer akun akan menerima permintaan pembayaran, mengidentifikasi pelanggan, dan memproses permintaan pembayaran. Proses identifikasi termasuk memeriksa dana yang tersedia dan jumlah yang diminta $[15,16]$. Ketika proses selesai, pemberitahuan pembayaran diteruskan ke Pusat Data sebagai layanan pembayaran. Pusat data kemudian mengidentifikasi alamat operator bank / telco pada pemberitahuan pembayaran dan kemudian mengirimkan pesan kepada pedagang untuk memberi tahu bahwa proses pembayaran telah terjadi. Prosesor di sisi pedagang menerima pemberitahuan pembayaran dan memberikan pemberitahuan waktu-nyata tentang apakah transaksi diterima atau ditolak.

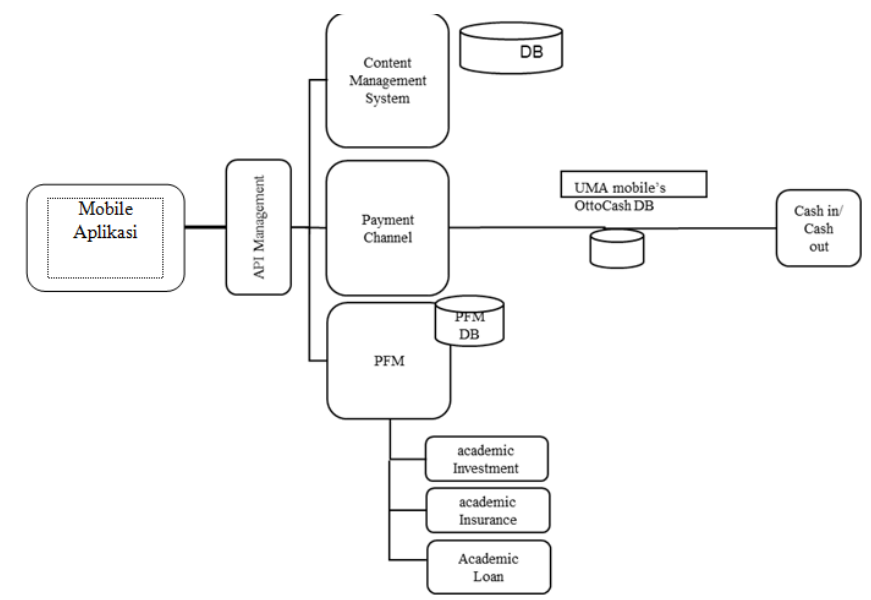

Gambar 1. Arsitektur Dasar Pembayaran Seluler 
Gambar 1. fintech menggunakan manajemen API sebagai perantara yang memfasilitasi pertukaran informasi atau data antara dua atau lebih aplikasi perangkat lunak yang terintegrasi dengan sistem manajemen konten, saluran pembayaran dan manajemen keuangan pribadi (PFM). Dalam sistem manajemen konten, data yang ada disimpan untuk ditambahkan atau diedit. Dalam saluran pembayaran, pedagang yang ada dipilih oleh pengguna untuk transaksi $[17,18]$. Setiap transaksi yang dilakukan diperiksa ulang kebenaran data dan diberikan asuransi. Setelah menyelesaikannya segera, tahap selanjutnya adalah pembayaran dengan menggunakan akun virtual atau pembayaran langsung secara online $[19,20]$.

\section{HASIL DAN PEMBAHASAN}

Pada langkah pertama, setiap pengguna mendaftar dengan mengisi data pribadi mereka. Setelah pendaftaran, pengguna dapat masuk untuk memasuki sistem. Berbagai jenis pedagang disediakan di sistem. Pengguna dapat memilih salah satu pedagang yang tersedia untuk melakukan pembayaran. Selama proses pembayaran, ada beberapa pilihan yang diberikan, pembayaran melalui Indomaret atau pembayaran menggunakan akun virtual (jika sudah ada saldo). Saldo dapat diisi ulang oleh sistem. Itu bisa dilihat pada Gambar 3.

\subsection{Spesifikasi fitur:}

a) Registrasi Pengguna

b) Penambahan Saldo

c) Transfer P2P

d) Transfer ke teman

e) Transfer ke Rekening Bank

f) Pembayaran dengan QR

g) pembelian dan pembayaran tagihan

h) Pembelian Paket Kredit dan Data

i) Telkom, Air, BPJS, Pembayaran Tagihan TV Kabel

j) Pembayaran Tiket Perjalanan (Kereta Api)

k) Pemberitahuan Push

l) Kirim Hadiah

m) Transaksi Historis

\subsection{Fitur Tambahan:}

a) Manajemen Keuangan Pribadi (PFM) Penilaian analisis keuangan pribadi

b) Penilaian kesehatan keuangan pribadi

c) Layanan rekomendasi Produk Finansial yang terdiri dari produk Investasi dan Asuransi.

d) Alat untuk memantau dan mengontrol tingkat pengeluaran untuk memenuhi tujuan perencanaan keuangan pelanggan.

Dari hasil yang pengembangan aplikasi maka dapat kami peroleh untuk menambahkan beberapa fitur sesuai dengan kebutuhan pengguna yang didalamnya sesuai dengan perkembangan elaborasi aplikasi yang lain. Aplikasi yang dikembangkan dapat menjaring konektifitas antar muka yang selama ini dibangung dengan mengedepankan API dalam proses didalamnya. Teknik PFM ini 
dapat dengan mudah mengatur keuangan masing-masing pengguna saat menggunakannya. Sehingga mampu menjawab kebutuhan teknologi keungangan secara digital mendatang.

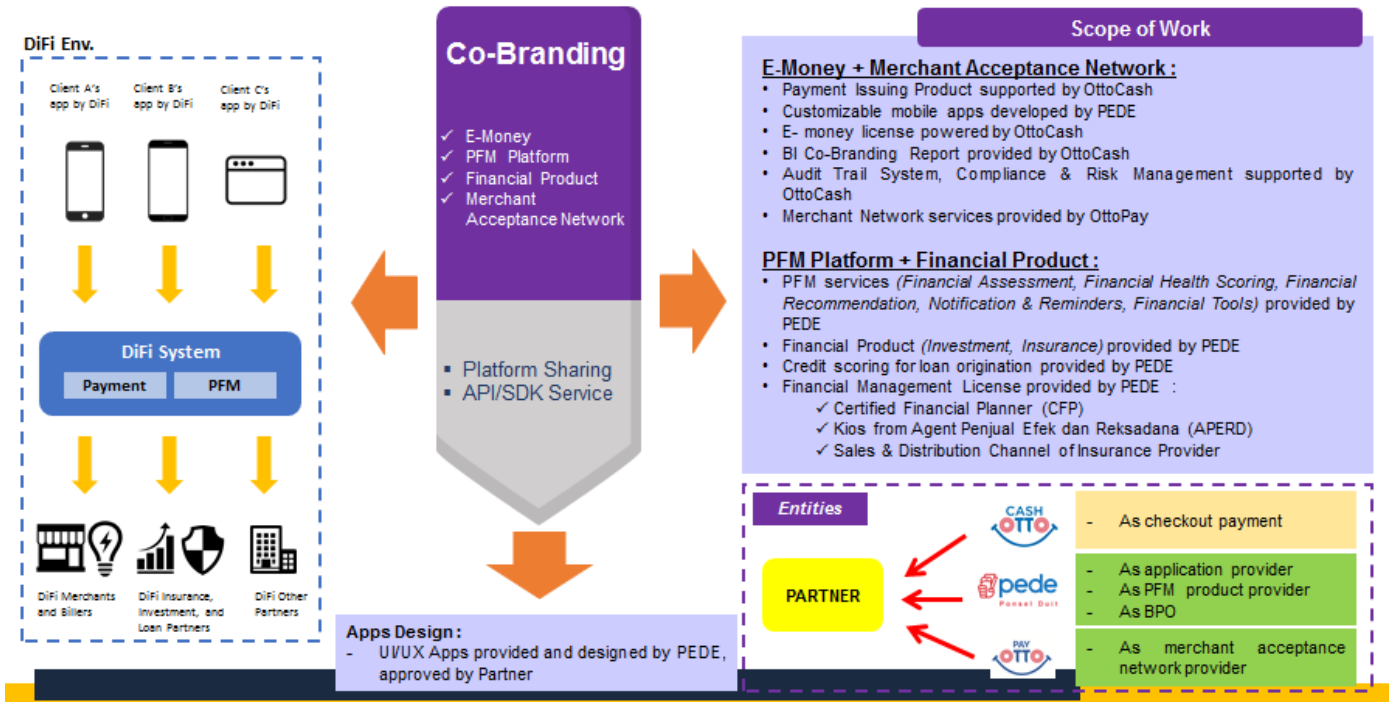

Gambar 2. Arsitektur Dasar Pembayaran Seluler untuk Akademik

Gambar 2. Kerangka kerja untuk aplikasi yang dibangun berdasarkan kebutuhan lingkungan kampus, terutama di wilayah Universitas Medan. Aplikasi ini dibangun dengan tujuan untuk memfasilitasi siswa dan pemangku kepentingan di lingkungan kampus dalam proses layanan kualitas akademik. Ini membutuhkan skema technopreneurship komprehensif yang dilakukan oleh kampus. Salah satu metode yang kami gunakan dalam mengelola lingkungan kampus melalui PFM yang berfungsi sebagai tabungan untuk manajemen keuangan independen dilakukan oleh mahasiswa dan pembuat kebijakan di lingkungan kampus. Siswa juga dapat memberikan pinjaman uang kuliah atau saran praktis dengan menggunakan aplikasi ini. Tidak hanya itu, setiap pembayaran uang sekolah dapat dilakukan di mana saja dan kapan saja selama pengguna aplikasi dapat melakukan Top Up di aplikasi ini. Pendekatan teknologi pembayaran digital telah membawa perubahan dalam menyediakan akses langsung.

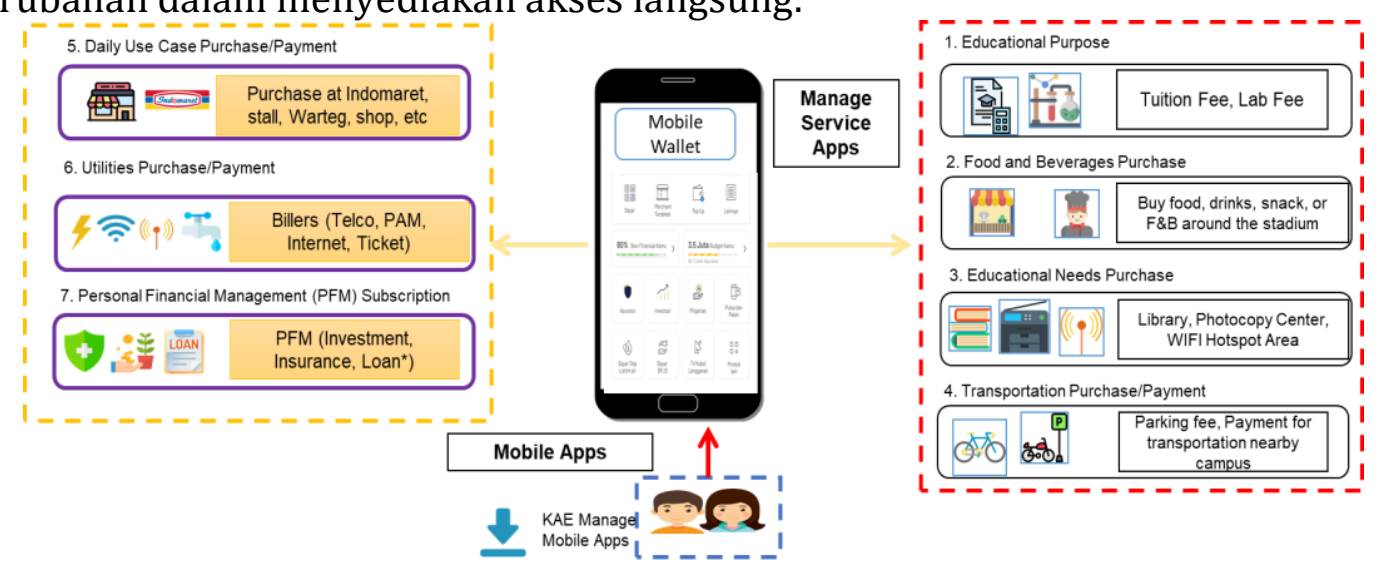

Gambar 3. Aktivitas Akademik dalam Pembayaran Seluler 
Gambar 3. Dalam penelitian ini, aplikasi yang ditawarkan untuk memfasilitasi siswa dalam kegiatan mereka dalam menggunakan dompet ponsel dengan tujuan semua kegiatan dapat dengan mudah dikendalikan oleh keluarga, dan kampus. Metode ini disebut percepatan pengukuran pengetahuan yang dituangkan ke dalam basis informasi dalam studi proses belajar mengajar serta kontrol siswa dan pengguna.

\section{KESIMPULAN}

Manajemen Keuangan Pribadi dalam Aplikasi akademik, fintech secara global menunjukkan bahwa ia berkembang pesat di berbagai sektor, mulai dari pembayaran awal, pinjaman, perencanaan keuangan (keuangan pribadi), investasi ritel, crowdfunding, pengiriman uang, riset keuangan, dan lain-lain. Peran Fintech meluas ke berbagai aspek seperti layanan pembayaran digital dan pengaturan keuangan, kemudahan memilih produk sesuai dengan kebutuhan, dan kemudahan pembayaran dan manajemen keuangan.

\section{ACKNOWLEDGMENT}

Penelitian ini didukung oleh Kampus Universitas Medan Area, dan didanai sesuai dengan kebutuhan lingkungan kampus Universitas Medan Area. Penelitian akan didaftarkan dalam HKI (Hak Kekayaan Intelektual).

\section{DAFTAR PUSTAKA}

[1] R Syah, M.K.M Nasution, E B Nababan, S Efendi. (2020). Knowledge Acceleration Estimator (KAE) Model to Customer Behavior Using Business Metrics. Journal of Theoretical and Applied Information Technology (JATIT). Vol. 98 April 2020.

[2] Reiss, D. G. (2018). Is money going digital? An alternative perspective on the current hype. Financial Innovation, 4(1), 1-6.

[3] Varga, D. (2017). Fintech, the new era of financial services. Vezetéstudominy-Budapest Management Review, 48(11), 22-32.

[4] Chen, G., Xu, B., Lu, M., \& Chen, N. S. (2018). Exploring blockchain technology and its potential applications for education. Smart Learning Environments, 5(1), 1.

[5] Yan, J., Yu, W., \& Zhao, J. L. (2015). How signaling and search costs affect information asymmetry in P2P lending: the economics of big data. Financial Innovation, 1(1), 19.

[6] Kang, J. (2018). Mobile payment in Fintech environment: trends, security challenges, and services. Human-centric Computing and Information Sciences, 8(1), 1-16.

[7] Ruotsalainen, J., Heinonen, S., Karjalainen, J., \& Parkkinen, M. (2016). Peer-to-peer work in the digital meaning society 2050. European Journal of Futures Research, 4(1), 10.

[8] Hung, J. L., \& Luo, B. (2016). FinTech in Taiwan: a case study of a Bank's strategic planning for an investment in a FinTech company. Financial Innovation, 2(1), 15.

[9] M K M Nasution., M Hardi., R Syah. 2017. Mining of the social network extraction. Journal of Physics: Conference Series 801 (1).

[10] R syah., T E Nuradi., M K M Nasutin. 2016. A framework to apply ICT for bequeathing the cultural heritage to next generation. Journal of Physics: Conference Series

[11] Sharad Sinha. 2017. FinTech: The New Frontier. IEEE Potentials (Volume:36, Issue:6, Nov.Dec. 2017 ).

[12] Moon, W. Y., \& Kim, S. D. (2016, October). A payment mediation platform for heterogeneous FinTech schemes. In 2016 IEEE Advanced Information Management, Communicates, Electronic and Automation Control Conference (IMCEC) (pp. 511-516). IEEE.

[13] Ma, Y., \& Liu, D. (2017). Introduction to the special issue on Crowdfunding and FinTech.

[14] Lin, Z., Whinston, A. B., \& Fan, S. (2015). Harnessing Internet finance with innovative cyber credit management. Financial Innovation, 1(1), 5. 
[15] R. Syah, M. K. M. Nasution, E B Nababan, S Efendi. (2019). Optimization Metrics Model : The Mobile Wallet for Merchant Ecosystem. International Conference on Computational Science and Information Management (ICCAI).

[16] Elveny, M., Syah, R., Elfida, M., \& Nasution, M. K. M. (2018, January). Information retrieval on social network: An adaptive proof. In IOP Conference Series: Materials Science and Engineering (Vol. 300, No. 1, p. 012055). IOP Publishing.

[17] Mahyuddin, K., Nasution, M., Elveny, M., Syah, R., \& Noah, S. A. (2015, August). Behavior of the resources in the growth of social network. In 2015 International Conference on Electrical Engineering and Informatics (ICEEI) (pp. 496-499). IEEE.

[18] Syah, R. (2014). Rancang Bangun Data warehouse untuk Analisis Strategi Produksi Penjualan Usulan: PT. XYZ. TECHSI-Jurnal Teknik Informatika, 6(1).

[19] Nasution, M. K., Hardi, M., \& Syah, R. (2017, January). Mining of the social network extraction. In Journal of Physics: Conference Series (Vol. 801, No. 1, p. 012020). IOP Publishing.

[20] Syah, R., Sajadin, S., \& Lubis, I. PEMANFAATAN PROSES ASSESMENT MODEL (PPAM) MENGGUNAKAN COBIT5 (Control Objectives for Information and related Technology) PADA PERGURUAN TINGGI.

[21] Syah, R. (2019). Pedekatan Model Fuzzy Time Series Dengan Analytic Hierarchy Process Untuk Peramalan Mahasiswa Berprestasi. TECHSI-Jurnal Teknik Informatika, 8(1), 148-156. 